\title{
Interdisciplinaridade, formação humana e emancipação humana
}

\author{
Interdisciplinarity, human development \\ and human emancipation
}

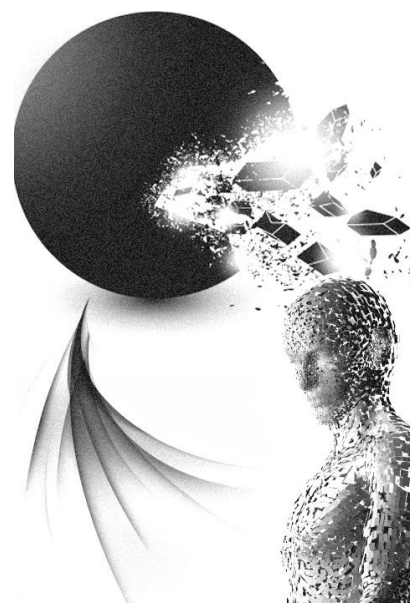

Ivo Tonet*

Resumo: O presente artigo tem como objetivo fazer a crítica das propostas que pretendem superar a fragmentação do saber através da interdisciplinaridade, da trans ou da multidisciplinaridade e de outras denominações semelhantes. Procuraremos demonstrar que essas propostas são um caminho equivocado para um problema mal equacionado. E que, como a fragmentação do saber não tem sua origem na esfera epistemológica, mas na esfera ontológica, então sua superação integral pressupõe, necessariamente, a transformação do mundo real que está na sua origem.

Palavras-chave: Fragmentação do saber. Interdisciplinaridade. Crítica.

\begin{abstract}
This article aims to be a critical counterargument to the propositions that intend to overcome the fragmentation of knowledge through interdisciplinarity, transdisciplinarity, multidisciplinarity and other similar denominations. We seek to demonstrate that these propositions constitute an erroneous path to a badly-equated problem. Moreover, as the fragmentation of knowledge does not originate from the epistemological sphere, but from the ontological one, then its integral overcoming necessarily depends on the transformation of the real word from which it stems.
\end{abstract}

Keywords: Fragmentation of knowledge. Interdisciplinarity. Ontological criticism.

* Mestre em Filosofia pela Universidade Federal de Minas Gerais (UFMG). Doutor em Educação pela UNESP-Marília. Professor de Filosofia da Universidade Federal de Alagoas (UFAL) Maceió, Brasil. E-mail: ivo_tonet@yahoo.com.br. 


\section{Introdução}

$\mathrm{F}$

ala-se muito, hoje, em interdisciplinaridade, transdisciplinaridade, multidisciplinaridade, pluridisciplinaridade e outras denominações semelhantes. Todas essas seriam formas de superar o problema da fragmentação do saber e da formação profissional.

Não é nossa intenção discutir, aqui, em detalhes, essa problemática. Não desconhecemos as diferenças que são feitas entre as várias denominações acima referidas e entre a interdisciplinaridade na pesquisa científica e na ação pedagógica. Também não é nosso objetivo discutir a interdisciplinaridade entendida como proposta epistemológica e como atitude pedagógica.

Nossa intenção, nesse texto, é fazer uma crítica dos fundamentos da proposta da interdisciplinaridade, demonstrando que, apesar do seu caráter atraente e dos seus aparentes resultados, é uma solução equivocada para um problema mal equacionado.

\section{Estado da questão}

Há uma sensação generalizada e causadora de mal-estar de que o conhecimento está excessivamente fragmentado; de que cada disciplina trata isoladamente de um determinado aspecto - econômico, histórico, sociológico, psicológico, filosófico, artístico etc. - e que, assim, não é possível adquirir uma visão de conjunto dos objetos estudados. O resultado disto é uma formação construída com fragmentos desconexos e justapostos. Em consequência dessa visão fragmentada da realidade, a intervenção prática para o enfrentamento dos problemas sociais também se vê comprometida, levando a buscar soluções isoladas.

Para essa formação fragmentada colaboraria, também, a intensa especialização, que levaria a uma concentração cada vez mais localizada em aspectos restritos, tornando, de novo, o indivíduo incapaz de uma percepção da totalidade.

A causa mais comum dessa fragmentação é atribuída à crescente complexificação da realidade social e à consequente ampliação do território do conhecimento. Salta aos olhos a enorme amplitude que esse território adquiriu, em especial na modernidade. É um fato amplamente reconhecido o avanço extremamente rápido 
do conhecimento nos mais variados aspectos a partir do Renascimento. Se na Antiguidade era admissível a existência de uma figura enciclopédica como Aristóteles, que não era a única, mas certamente a maior, e no Renascimento ainda podemos admirar uma mente que dominava saberes tão vastos e diversificados como Leonardo da Vinci, hoje seria impensável, diante da vastidão do que já foi descoberto, que alguém pudesse abarcar, minimamente, o conjunto do conhecimento. A revolução industrial e a disseminação do capitalismo por todo o globo terrestre também contribuíram enormemente para a ampliação e a variedade dos domínios do saber. Daí a crescente especialização, necessária para o domínio, em profundidade, de um determinado campo do saber. A consequência dessa ampliação e dessa especialização seria, segundo os cultores da interdisciplinaridade, a compartimentação e o isolamento cada vez mais intensos de cada campo do saber. Assim, complexificação, especialização e fragmentação seriam consequências necessárias na trajetória do processo social.

Diante do reconhecimento das consequências negativas desse processo, busca-se encontrar uma solução que restitua ao conhecimento aquele caráter de totalidade que permita, tanto na realização de pesquisas teóricas, como na formação profissional e no tratamento dos problemas sociais, superar aquela visão atomizada dos objetos. Daí o surgimento das propostas de inter, trans, multi, pluridisciplinaridade. Por mais que haja diferenças entre essas propostas, o cerne da questão é que a abordagem de um mesmo objeto sob vários aspectos, no caso das ciências humanas - filosófico, econômico, sociológico, histórico etc. - seria o caminho para a superação dessa fragmentação do saber. Por outro lado, a própria realidade indicaria a necessidade de evitar a rigidez da compartimentação. O recente surgimento de alguns novos campos da ciência, cujos limites são bastante fluidos, evidenciaria que é praticamente impossível definir claramente onde começa e onde termina um determinado território científico.

Esse modo de pensar se tornou extremamente atraente, dando origem a teorizações sistematizadas e sendo incorporado, no Brasil, nos PCNs (Parâmetros Curriculares Nacionais). Tão atraente que dificilmente se imaginaria alguém fazendo uma crítica no sentido de afirmar que se trata de um equívoco.

Poderíamos perguntar, ao final dessa introdução, por que esse modo de pensar se torna tão atraente? E por que sua atração é tanta que, provavelmente, o fato de o questionarmos provocará, imediatamente, uma reação de espanto ou de rejeição? 
Essa atração decorre, a nosso ver, do seu caráter de obviedade, do fato de se apoiar em aspectos empíricos verdadeiros e facilmente identificáveis, de se apresentar como a única via para superar a fragmentação do saber e de apresentar resultados aparentemente positivos.

É um fato que houve, ao longo da história da humanidade, mas especialmente, nas últimas centenas de anos, e mais ainda nas últimas dezenas, uma grande complexificação da realidade social e uma enorme ampliação do território do saber. Também é incontestável que isso levou a uma especialização crescente, dada a impossibilidade de um indivíduo só dominar o conjunto do saber e dado o surgimento de novos campos de atuação profissional. Ao longo desse processo, foram sendo criadas inúmeras disciplinas sem conexão entre si, fazendo da pesquisa e do ensino uma autêntica colcha de retalhos. Em consequência, a formação se dá pela justaposição de pedaços desconexos, impedindo uma visão de totalidade. Do mesmo modo, também são visíveis os variados e complexos problemas sociais que foram surgindo a partir da revolução industrial e a impossibilidade de resolver cada um deles de modo isolado.

Diante disso, parece que, de fato, o trabalho interdisciplinar é um procedimento que tem resultados imediatos positivos. Pois, é certamente verdade que a soma de aspectos econômicos, sociológicos, filosóficos, históricos e outros, trará um conhecimento mais ampliado do que se esse tratamento se limitasse a apenas uma dessas áreas. Por outro lado, um conhecimento mais amplo permitiria um tratamento menos isolado de cada problema, seja no âmbito profissional, seja na esfera da ação social.

Tudo isso confere a esse modo de pensar essa aura de obviedade, pois entre disciplinaridade (fragmentação) e interdisciplinaridade (unificação) a escolha só poderia ser óbvia.

Em resumo, entre a fragmentação resultante da compartimentação do saber e a ação focalizada sobre os problemas sociais, de um lado, e a visão de totalidade que seria fornecida pela interdisciplinaridade e a possibilidade de uma ação social que considerasse os vários aspectos como partes de uma totalidade, de outro lado, não há dúvida que esta última alternativa é, obviamente, a mais atraente. Ela se impõe com o poder de algo inteiramente evidente.

Deste modo, não se trataria de discutir a validade da interdisciplinaridade, mas apenas as suas formas concretas. E é sobre isso que se debruçam autores conhecidos, no Brasil, como Ivani Fazenda, Hilton Japiassú e Antônio Joaquim Severino, entre outros. 


\section{Os equívocos desse modo de pensar}

A contrapelo dessas ideias dominantes, defendemos a tese de que esse modo de pensar é profundamente equivocado. E que a interdisciplinaridade é uma solução equivocada para um problema mal-equacionado.

Por que isso? Em primeiro lugar, porque pressupõe que a complexificação e a fragmentação são simplesmente resultados naturais do processo social, sendo a segunda uma consequência necessária da primeira.

Em segundo lugar, porque desfaz a dependência ontológica do conhecer em relação ao ser. Por mais que faça referência ao processo histórico que levou à fragmentação do saber, não percebe, ou não aceita, a relação de dependência ontológica do conhecimento em relação às condições materiais. Deste modo, termina por atribuir ao conhecimento uma autonomia que ele de fato não tem, tratando, assim, a fragmentação do saber como um processo que se dá no interior do próprio saber.

Daí porque também se impõe como algo evidente a necessidade de refazer a totalidade perdida, através da reaproximação desses novos campos.

Pressupõe-se, portanto, que, da soma desses diversos fragmentos, é possível obter um conhecimento totalizante de um determinado objeto.

Em terceiro lugar, porque, pressupondo a autonomia do saber, não toma como ponto de partida uma crítica do próprio processo material de fragmentação. Sua teorização se limita a buscar superar a fragmentação pelas vias epistêmica, pedagógica ou comportamental.

Em quarto lugar, porque toma o padrão moderno de cientificidade como o verdadeiro caminho para a produção do conhecimento científico, ignorando que a fragmentação do saber faz parte da natureza desse padrão e que a origem dessa cisão não está no próprio saber, mas no solo social que lhe deu origem.

Em quinto lugar, porque, ao tomar o padrão moderno de cientificidade como o verdadeiro caminho para a produção do conhecimento científico, também ignora que este padrão tem no sujeito o polo regente do conhecimento, o que resulta, como veremos, em graves e negativas consequências.

Passemos, então, a um exame crítico dessa problemática. 


\section{Equacionando o problema}

Parafraseando Marx, em sua referência à religião, poderíamos afirmar que a crítica da interdisciplinaridade não é a crítica da interdisciplinaridade, mas a crítica do mundo que produz e necessita dessa forma de produção do saber. A questão inicial e fundamental, então é: que mundo é este?

Considerando, pois, esse pressuposto, antes de propor qualquer fórmula de superação da fragmentação do saber é preciso explicar esse fenômeno e não aceitá-lo como um fato natural. É necessário compreender, desde suas raízes materiais, o processo que levou a esse resultado. Contudo, a compreensão desse processo não pode partir de um momento já bem avançado do ser social que é a modernidade. Partir da modernidade é tomar como ponto de partida uma situação que já é o resultado de um determinado processo histórico. Seria, de novo, tomar como pressuposto exatamente aquilo que deve ser explicado.

Para entender como se chegou até esta situação faz-se necessário apreender a trajetória do ser social a partir dos seus fundamentos originais, tanto em termos históricos como em termos ontológicos. Em termos históricos, porque a própria modernidade já é o resultado de uma longa trajetória. E em termos ontológicos, porque é preciso buscar, na natureza do ser social, os fundamentos que deram origem ao processo de fragmentação.

Somente assim se poderá compreender tanto a natureza mais profunda da realidade social quanto os seus desdobramentos ao longo da história. Vale dizer, só é possível compreender tanto o processo de complexificação quanto o de fragmentação apreendendo o caráter unitário do ser social e o processo social que deu origem à quebra dessa unidade. E isto, tanto em termos da sua materialidade quanto no que se refere ao processo de conhecimento. Para isso, é preciso partir do ato fundante do ser social. Na esteira de Marx, pressupomos que esse ato é o trabalho. ${ }^{1}$

É a partir da análise do trabalho e de suas relações com as demais dimensões do ser social - tais como linguagem, socialidade, arte, ciência, política, direito, educação, filosofia etc. — que se compreende que o ser social é uma totalidade,

1. A esse respeito, ver, de K. Marx, Manuscritos econômico-filosóficos e O capital; de G. Lukács, Ontologia dell'Essere Sociale, Prolegômenos para uma ontologia do ser social e As bases ontológicas do pensamento e da atividade do homem; de S. Lessa, Mundo dos homens; de José Paulo Netto e Marcelo Braz, Economia política: uma introdução crítica, capítulo 1. 
isto é, um conjunto de partes articuladas, em constante processo. O trabalho, esse intercâmbio do homem com a natureza, através do qual são produzidos os bens materiais necessários à existência humana, é o ato que funda o mundo social. Porém, a própria realização do trabalho exige a intervenção de outras dimensões, como linguagem, socialidade, conhecimento, educação para a sua realização. Por outro lado, a complexificação da sociedade a partir do trabalho faz surgir novas situações, problemas e necessidades que demandam outras dimensões sociais para o seu enfrentamento. Pense-se na arte, na religião, na ciência, na política, no Direito. Nenhuma dessas dimensões é trabalho, mas todas têm a sua origem a partir do trabalho. Vale dizer, todas elas têm uma dependência ontológica em relação ao trabalho. O ser social, assim, é, na feliz expressão de Lukács, um complexo de complexos, mas matrizado pelo trabalho. Desse modo, fica claro que a categoria da totalidade, antes de ser uma categoria epistemológica é uma categoria ontológica, isto é, constitutiva da própria natureza essencial do ser social.

A análise do trabalho também nos permite perceber que ele é uma categoria que remete sempre para além de si mesmo, vale dizer, que possibilita a criação permanente do novo e não a simples reposição do mesmo como acontece no reino animal. Deste modo, é próprio do ser social tornar-se cada vez mais complexo e universal. Isto significa que a complexificação não é um defeito, mas uma determinação ontológica do ser social.

É também a partir da análise do trabalho - uma síntese entre teleologia e causalidade, ou consciência e realidade natural - que se compreende que o conhecimento é um momento que, juntamente com a realidade natural, constitui uma unidade indissolúvel, cuja efetivação resulta na constituição da realidade social. Porém, esta análise também permite compreender que o conhecimento tem uma relação de dependência ontológica em relação ao trabalho. Repetindo Marx e Engels (1984, p. 37): "Não é a consciência que determina a vida, mas a vida que determina a consciência". Isto significa, sem nenhuma relação mecânica, mas levando em conta todas as mediações insuprimíveis, que a forma do trabalho, ou seja, o modo como os indivíduos concretos se relacionam entre si no processo de transformação da natureza, é o fundamento da forma como se estrutura o conhecimento da realidade. Como síntese e exemplo disto poderíamos dizer que a cientificidade (não simplesmente a ciência) do mundo moderno é a forma do fazer científico historicamente condicionada pelo mundo moderno.

Trata-se, então, de compreender, a partir dessa unidade originária do ser social, como se deu, ao longo da história, seu processo de entificação, que levou tanto à 
complexificação e à especialização quanto à fragmentação e isso tanto na realidade material quanto no âmbito do conhecimento.

Partindo-se, pois, desse ato fundante do ser social, que é o trabalho, pode-se perceber como a complexificação é uma característica ontológica, e por isso insuprimível, do ser social. Dos grupos primitivos e mais simples ao mundo atual, temos um processo ao longo do qual a realidade social vai se tornando cada vez mais complexa e universal. Por seu lado, a complexificação resulta, necessariamente, na especialização pois, de fato, é impossível a um único indivíduo abarcar a totalidade do fazer e do saber sociais.

Porém, a entrada em cena da divisão social do trabalho e da propriedade privada imprimem a essa complexificação uma especificidade própria e radicalmente diferente daquela que existia no interior da comunidade primitiva. Opera-se, então, no interior do ser social, uma profunda cisão. Trata-se da divisão entre trabalho manual e trabalho intelectual. Esta divisão não é, de modo nenhum, natural, embora adquira um caráter de naturalidade. Pelo contrário, resulta de um processo claramente social. Saber e fazer são separados e essa separação é justificada teoricamente e contribui poderosamente para manter a exploração e a dominação de classes.

Essa cisão ganha uma forma toda particular na sociedade burguesa através da fragmentação no interior do próprio processo de trabalho. Como se sabe, esta fragmentação faz do trabalhador uma mera peça na engrenagem de produção, impedindo-o de ter o conhecimento e o controle da totalidade do processo produtivo. Este conhecimento e este controle são detidos pelo capital e são instrumento fundamental de sua dominação sobre o trabalho. Além disso, pelo processo de fetichização, cuja origem está na forma específica da produção da mercadoria, a realidade social é recoberta por um caráter de naturalidade. Deste modo, tanto a fragmentação do processo de trabalho como do conhecimento se apresentam como desdobramentos naturais na atual forma da realidade social.

\section{A crítica desse modo de pensar}

Partindo dessa materialidade do mundo moderno, podemos entender por que a fragmentação é uma característica típica da cientificidade moderna e por que é equivocada a proposta da interdisciplinaridade. 
Sabe-se que a ciência moderna surgiu no período de transição do feudalismo ao capitalismo. O cerne dessa transição — no âmbito do conhecimento — se situa na passagem da centralidade do objeto (na concepção greco-medieval) para a centralidade do sujeito (na concepção moderna). Mas, é importante acentuar que essa mudança se deveu, em primeiro lugar, às transformações materiais que se deram nesse período. A um mundo largamente estático, finito e hierarquicamente ordenado, sucedeu-se um mundo em rápidas transformações, cada vez mais amplo e sem nenhuma hierarquia. A uma ordem social diante da qual o sujeito se via apenas como expectador e contemplador, sucedeu-se uma ordem na qual o homem se via como construtor ativo, tanto prática como teoricamente. Conhecer o mundo, especialmente a natureza, para transformá-lo se tornou a característica central desse novo modo de estar no mundo.

Resumindo um processo extremamente complexo e de longa duração, podemos recorrer a Kant, não por acaso conhecido como aquele que realizou, na problemática do conhecimento, a mesma revolução efetivada por Copérnico na concepção de mundo. Daí ser ele conhecido como autor da "revolução copernicana" na concepção do conhecimento. Em síntese, essa revolução significava que, em vez de o objeto ser o polo regente do conhecimento, seria o sujeito a ocupar esse lugar. As causas dessa mudança estão nas transformações que o mundo sofreu ao longo desse período, gerando a demanda por um novo padrão de conhecimento.

Tendo perdido os fundamentos da ordem do mundo que, na concepção greco-medieval, estariam na natureza do próprio mundo (na sua essência), o homem precisava buscar esses fundamentos em si mesmo. O "cogito" cartesiano é emblemático disso, assim como o empirismo típico inglês. Eis porque, ao contrário dos gregos e medievais, para os quais a primeira tarefa era a elaboração de uma teoria geral do ser, os pensadores modernos começam por elaborar uma teoria do conhecimento, buscando construir fundamentos considerados mais sólidos para o novo tipo de saber.

Mas, essa busca dos fundamentos no interior da própria subjetividade implicava a impossibilidade e a nulidade de buscar a essência das coisas e, portanto, de encontrar a ordem estabelecida pela hierarquia das essências inerente à própria realidade, como propunha a concepção greco-medieval. Na concepção moderna, a mediação inescapável entre a subjetividade e a realidade do mundo são os dados dos sentidos. Nenhum conhecimento seria científico se não se apoiasse nesses dados e se extrapolasse o campo por eles permitido. Porém, esses dados são, em si mesmos, 
sempre singulares, parciais, múltiplos e caóticos. Faz-se, então, necessária a intervenção da razão para ordená-los.

Propondo-se a superar o dissenso, sobejamente conhecido entre racionalismo e empirismo, Kant elabora a sua síntese que implica a articulação entre razão e dados da sensibilidade. Os sentidos colhem os dados e a razão classifica, organiza, extrai as legalidades e elabora uma teorização a partir deles. Deste modo, o objeto de conhecimento já não é o mundo real, mas aquilo que o sujeito constrói a partir dos dados colhidos pelos sentidos.

A consequência lógica, também extraída por Kant, é que nós não podemos conhecer a "coisa em si" (o númeno); só podemos conhecer a coisa como ela é para nós (o fenômeno). Vale dizer, por esse andamento, a categoria da essência, tão cara à concepção greco-medieval, se torna inatingível e a categoria da totalidade se transforma em uma categoria puramente lógica. A realidade já não é mais um compósito de essência e aparência, mas apenas fenômeno. Por isso mesmo, a ordem do mundo já não se encontra nele, mas é o sujeito que imputa ao mundo um determinado ordenamento.

Em síntese, nessa transição do mundo greco-medieval ao mundo moderno há uma passagem de uma perspectiva ontológica - centralidade do ser, embora de caráter metafísico - para uma perspectiva gnosiológica - centralidade do conhecer.

Por outro lado, na origem da ciência moderna também encontra-se uma acirrada disputa entre a concepção de mundo cristã e as novas tendências profanas do conhecimento. Disputa que, como se sabe, não era meramente teórica, mas tinha consequências práticas da maior gravidade. A solução intermediária encontrada foi atribuir a cada ciência a competência de falar sobre um determinado campo restrito da realidade. À religião se reservava a competência de elaborar uma visão de mundo totalizante. Deste modo, as diversas ciências se viam impedidas de extrair das suas pesquisas considerações a respeito do mundo em geral.

Mas, havia ainda outro aspecto da maior importância. Como se sabe, a sociedade burguesa é marcada, como nenhuma outra anterior, por uma intensa divisão social do trabalho, resultado da própria lógica de produção e reprodução do capital. Divisão esta que se acentuou extraordinariamente com a entrada em cena da revolução industrial.

Como a sociedade burguesa seria a expressão da própria natureza humana ("socialmente insociável", no dizer de Kant), nada mais justo que essa divisão do 
trabalho fosse considerada o modo natural de manifestar-se dessa natureza. A naturalidade dessa divisão social do trabalho, por sua vez, esteve na origem das chamadas ciências humanas, cada uma delas surgindo a partir da delimitação de um território específico. Essa delimitação partia do pressuposto de que a realidade social não era um conjunto de partes intimamente articuladas, mas uma soma de partes sem conexão essencial entre si. Daí porque cada uma das disciplinas - economia, sociologia, ciência política, psicologia, antropologia etc. — poderia reivindicar o tratamento isolado de uma parte da realidade social.

Ora, a teoria da interdisciplinaridade, como vimos acima, não tem como ponto de partida uma teoria da fragmentação. Vale dizer, não começa buscando uma explicação para o processo de fragmentação do saber. Apenas reconhece esse fato e as suas consequências negativas. Mesmo quando faz referência à fragmentação do processo produtivo capitalista, a conexão desta com o que acontece na dimensão científica é muito tênue. Deste modo, a proposta de superação da fragmentação do saber ganha um caráter marcadamente subjetivo. Deixando de lado as raízes materiais da fragmentação do conhecimento, e mesmo admitindo que este é um processo natural, pressupõe que se trate de um problema meramente epistêmico e que, portanto, pode ser superado também no plano epistêmico. Quando muito, além desse plano meramente epistêmico também se agrega um plano moralista, enfatizando a necessidade de ter atitudes pedagógicas integradoras.

Por sua vez, a articulação entre o caráter fenomênico da cientificidade moderna, ao qual já aludimos acima, e o fetichismo da mercadoria, faz com que a realidade social seja resumida à aparência, ao fenômeno, aos dados empíricos, perdendo-se, deste modo, as categorias da totalidade e da essência, que, como vimos, são constitutivas da natureza do ser social.

Vale lembrar, ainda, que a constituição da sociedade burguesa é um processo que, começando por volta do século XV, continua até hoje. No interior dele, podemos distinguir dois grandes momentos. $\mathrm{O}$ momento de ascensão, que vai do século XV até a metade do século XIX. Nesse período, a burguesia, que é o sujeito fundamental desse processo, é uma classe revolucionária, ou seja, está impulsionando a abertura de uma nova forma de sociabilidade, mais favorável ao desenvolvimento da humanidade. Para isso, ela precisa de uma forma de conhecimento mais adequada a esse novo empreendimento. Daí a necessidade de um conhecimento da natureza e da própria realidade social de caráter mais empírico e não especulativo. Como o seu antagonista é a nobreza feudal e ainda não o proletariado, sua deman- 
da por um conhecimento mais verdadeiro da realidade, inclusive social, pode ter um impulso muito positivo. Ainda que não seja um padrão de conhecimento que vá até a raiz do ser social ou que se equivoque na identificação dessa raiz, trata-se de uma aproximação à realidade bem mais efetiva do que aquela proporcionada pela perspectiva greco-medieval. Exemplos desse impulso positivo são autores como Maquiavel, na política, Smith e Ricardo, na economia, Vico, na história e Bacon e Galileu, no âmbito da ciência.

Contudo, esse impulso positivo sofre uma profunda inflexão negativa quando a burguesia se torna classe dominante. A partir desse momento, a burguesia tem necessidade de bloquear uma compreensão mais profunda da realidade social. Trata-se, da perspectiva dessa classe, de compreender a realidade social na forma e até o limite que permita a reprodução dessa ordem social considerada, não por acaso, a mais consentânea com a natureza humana. Nada disso é intencional no sentido conspirativo, mas certamente é intencional no sentido de que os pensadores têm consciência do que estão fazendo e acreditam que esse é o caminho mais adequado para a humanidade.

É exatamente nesse momento que se constituem as chamadas Ciências Sociais. Respondendo à fragmentação da materialidade do ser social, mas também à necessidade de justificar a nova forma da sociabilidade, elas se configuram ao redor de dimensões isoladas da realidade social, que só se conectam entre si de forma inteiramente superficial e a critério do próprio sujeito. Temos, assim, a economia, a sociologia, a ciência política, a psicologia, a antropologia etc., e, em cada uma delas, muitas subdivisões, todas elas delimitando seus campos de estudo e seus métodos de abordagem dos objetos como se fossem partes inteiramente autônomas.

Ora, ao eliminar as categorias da totalidade e da essência da realidade social, joga-se, necessariamente, sobre os ombros do sujeito a tarefa de realizar os recortes do objeto a ser estudado e de conferir unidade aos dados empíricos. A aparência e o empírico se tornam a matéria sobre a qual trabalha a cientificidade moderna. Como expressa muito bem José Paulo Netto, referindo-se às "duas posições fundamentais em face do conhecimento do social, no âmbito do racionalismo contemporâneo" (1989, p. 143):

A primeira $[\ldots]$ concebe a análise dos fenômenos a partir de sua expressão empírica [...]. Nesta ótica, o trabalho teórico tem na sistematização operada sobre o material empírico (seleção, organização, classificação, tipificação, categorização) um patamar prévio: é sobre ela que a teoria se estrutura, produzindo um símile ideal que procura 
contemplar a organização interna da empiria abordada através de um rigoroso tratamento analítico. A resultante da elaboração teórica, o produto teórico por excelência, é um modelo que a razão elabora e cria a partir do objeto empiricamente dado.

\section{A superação da fragmentação do saber}

Do que foi dito até aqui infere-se que a fragmentação do saber tem sua origem na divisão social do trabalho surgida com a propriedade privada e, na sua forma específica moderna, na fragmentação do processo capitalista de produção da riqueza material e é funcional à reprodução deste. Não por acaso, esta forma de sociedade é que permite a exploração do capital sobre o trabalho e, portanto, a manutenção dos interesses da classe burguesa. Ao impedir uma visão de totalidade do processo social e ao gerar uma compreensão desse mesmo processo apenas em sua aparência, esta forma de saber contribui para reproduzir um tipo de sociedade que favorece os interesses da burguesia.

Não há, pois, a menor possibilidade de superar a fragmentação do saber pela via puramente epistemológica e nem mesmo por nenhum esforço pedagógico ou comportamental. E mais ainda: quanto mais perdura esta forma de sociabilidade, mais se intensifica a fragmentação, pois isto é da lógica do capital e, portanto, mais forte se torna a mistificação do saber, independente de quantos esforços forem envidados para superá-la por via puramente epistemológica.

A efetiva superação dessa cisão no âmbito do saber passa, necessariamente, pela transformação radical do mundo que deu origem e necessita dessa forma de produção do conhecimento. Somente a constituição de um mundo que elimine a divisão social do trabalho e, portanto, a separação entre interesse particular e interesse geral, entre trabalho manual e trabalho intelectual, que suprima as classes com seus interesses antagônicos, vale dizer, um mundo que seja uma totalidade humana não cindida, somente neste mundo será possível superar, integralmente, a fragmentação do saber. Em resumo, somente uma forma de sociabilidade comunista pode superar, efetivamente, o caráter fragmentado do saber, pois um saber unitário deve ter na categoria da totalidade a sua categoria fundamental. Ora, esta categoria, como já afirmamos mais acima, antes de ser gnosiológica é ontológica, isto é, expressa o caráter do próprio mundo.

Com isto, não queremos afirmar que não seja possível, hoje, produzir um conhecimento que não seja fragmentado. Pelo contrário, isto não só é possível como 
também necessário. Afinal, se um saber fragmentado é funcional à manutenção dos interesses da classe burguesa, um saber que tenha na categoria da totalidade a sua chave metodológica e que, pela articulação entre as categorias da essência e da aparência (de caráter histórico e social), permita a desmistificação da realidade social, é do interesse da classe proletária. Esta última, para orientar a sua luta no sentido de transformar o mundo todo e não apenas alguma parte; de superar radicalmente a exploração do homem pelo homem e de construir uma forma de sociabilidade que seja uma autêntica comunidade humana, precisa de um saber que permita compreender a realidade até a sua raiz — sua essência — e como uma totalidade. Afinal trata-se de transformar o mundo todo e não apenas alguma parte dele. Contudo, a produção de um saber não fragmentado passa, necessariamente, pela superação da centralidade da subjetividade, típica da cientificidade moderna. Seu caminho deverá passar pela centralidade da objetividade, de caráter histórico-social.

Ora, este tipo de saber, esse padrão metodológico originado e exigido pela classe trabalhadora foi exatamente aquele cujos fundamentos foram lançados por Marx. Como já argumentamos em outros textos, ${ }^{2}$ Marx lançou os fundamentos de uma concepção radicalmente nova de mundo, de um padrão de conhecimento profundamente novo e que, não por acaso, tem na categoria da totalidade a sua categoria fundamental. É este padrão que permite compreender a realidade social como um complexo de complexos que tem no trabalho a sua categoria ontológico-primária. É também este padrão que permite compreender a natureza própria do ser social, sua complexificação e sua fragmentação, tanto material como espiritual e a articulação entre esses dois momentos.

Como se pode ver, o mundo continuará sendo cada vez mais complexo e exigirá sempre novas especializações. Isto não implica, necessariamente, a fragmentação do conhecimento. Na medida em que a forma do trabalho tiver um caráter coletivo, social, tanto na produção como na apropriação da riqueza, e, portanto, eliminar a formação de classes sociais, a realidade social deixará de ser fragmentada e mistificada e, portanto, já não haverá necessidade de uma forma de saber que impeça sua compreensão como totalidade, até a sua raiz, e se transforme num instrumento de opressão e dominação.

Em resumo, complexificação e especialização fazem parte da natureza mesma do processo de reprodução do ser social. Pelo contrário, a fragmentação é um pro-

2. Marxismo para o século XXI e Educação, cidadania e emancipação humana, capítulo 1. Ver, também, de J. Chasin, Marx: estatuto ontológico e resolução metodológica. 
cesso social típico da sociedade de classes (no sentido da separação entre trabalho manual e trabalho intelectual) e, na sua forma mais desenvolvida, típico da sociedade capitalista.

Vale salientar que a superação da fragmentação no processo de produção da riqueza material e a superação da fragmentação no processo de produção do conhecimento são dois momentos articulados. Cada um tem uma especificidade própria, mas condicionam-se mutuamente nesta trajetória de construção de outra forma de sociabilidade. É preciso, contudo, acrescentar que, entre os dois, a fragmentação material é o momento fundamental. Sua eliminação é conditio sine qua non para pôr um fim efetivo à cisão no interior do saber.

Do que foi dito até aqui, seguem-se algumas consequências importantes.

Primeira: a forma atual do mundo, regida pelo capital, fundamenta e exige a fragmentação do saber como um instrumento necessário à sua reprodução. Por isso, enquanto o capital for a força dominante, a fragmentação do saber será também a forma dominante deste. Em síntese: um saber fragmentado é um saber de um mundo fragmentado.

Segunda: do ponto de vista estritamente científico, a superação da fragmentação não passa pela soma ou pela justaposição ou, ainda, por atitudes e esforços do sujeito em integrar várias áreas de conhecimento. A propósito disto, Lukács faz referência a Max Weber, um intelectual que abrigava em si variadas áreas de conhecimento. Ele era economista, sociólogo, historiador, filósofo e cientista político. No entanto, diz Lukács (1992, p. 123), “[...] não existe nele qualquer sombra de um verdadeiro universalismo". Essa incapacidade provinha, segundo Lukács, exatamente dos fundamentos metodológicos - típicos da cientificidade moderna — das ciências dominadas por Weber.

A eliminação da fragmentação do saber passa, sim, pela superação da perspectiva da cientificidade moderna, de caráter gnosiológico, onde o sujeito detém a centralidade, e pela apropriação da perspectiva metodológica (de caráter onto-metodológico) ${ }^{3}$ fundada por Marx, onde o objeto (de caráter histórico-social e não metafísico) tem a regência e o sujeito a tarefa ativa de traduzir

3. A esse respeito, ver, de G. Lukács, Ontologia Dell'essere sociale; O marxismo ortodoxo; "A ontologia de Marx: questões metodológicas preliminares"; de J. Chasin, Marx: Estatuto ontológico e resolução metodológica; de S. Lessa: Lukács: o método e seu fundamento ontológico e de I. Tonet, A questão dos fundamentos. 
teoricamente o processo social. Não basta ter boa vontade ou envidar esforços ou criar novos métodos a talante do sujeito. É preciso assumir e dominar o método que, tendo se originado, em seus fundamentos, do mundo, permita voltar a ele para compreendê-lo como uma totalidade e segundo a sua lógica própria e não ao arbítrio do sujeito.

Terceira: uma formação, em geral, voltada para a emancipação humana, hoje, só pode significar uma contribuição para o engajamento na radical superação da sociedade capitalista e na construção de uma sociedade comunista. Por isso, uma atividade teórica que se pretenda emancipadora passa, necessariamente, pela apropriação de um saber que permita a compreensão desta sociedade como uma totalidade, até a sua raiz mais profunda, e que também possibilite compreender a origem, a natureza e a função social da fragmentação, desmistificando, ao mesmo tempo, a sua forma atual.

\section{Concluindo}

Como se pode ver ao longo desse texto, a pretensão de superar a fragmentação do conhecimento através de uma reordenação epistêmica, mas sem o pressuposto da dependência ontológica do saber em relação ao mundo objetivo e sem buscar a origem, a natureza e a função social do processo de fragmentação, tanto material quanto intelectual e sem a superação da perspectiva moderna da cientificidade, pode ser muito atraente, porém é inteiramente equivocada e fadada ao insucesso. Não é a soma de partes justapostas que produz um conhecimento totalizante. Este só pode ser produzido a partir de fundamentos metodológicos radicalmente diversos daqueles que embasam a perspectiva da cientificidade moderna. Estes fundamentos implicam uma teoria geral do ser social (uma ontologia — histórico-social — do ser social) e tem na categoria ontológica da totalidade a sua chave mestra!

Deste modo, para todos aqueles que se propõem como objetivo contribuir com suas atividades teóricas para a construção de uma autêntica comunidade humana, plenamente emancipada, é imperativo o domínio da perspectiva metodológica - de caráter ontológico - à qual nos referimos acima, pois só ela permite a produção de um saber totalizante. Considerando que, para essa perspectiva, o real é sempre um complexo de complexos, então qualquer parte dele só pode ser 
efetivamente compreendida se remetida, com todas as mediações necessárias, para o todo do qual faz parte. Assim, produção de um saber totalizante e luta pela construção de um mundo unitário e emancipado são dois momentos de uma mesma atividade revolucionária.

Recebido em 26/3/2013 - Aprovado em 5/8/2013

\section{Referências bibliográficas}

BRASIL. Ministério da Educação. Secretaria da educação média e tecnológica. Parâmetros Nacionais Curriculares: Ensino Médio. Brasília: Ministério da Educação, 2002.

CHASIN, J. Marx: Estatuto ontológico e resolução metodológica. São Paulo: Boitempo, 2009.

FAZENDA, I. Interdisciplinaridade: história, teoria e pesquisa. Campinas: Papirus, 1994.

JAPIASSU, H. Interdisciplinaridade e patologia do saber. Rio de Janeiro: Imago, 1976.

KANT, I. Crítica da razão pura. Lisboa: Fundação Calouste Gulbenkian, 1989.

. Ideia de uma história universal de um ponto de vista cosmopolita. São Paulo: Brasiliense, 1986.

LESSA, S. Lukács: o método e seu fundamento ontológico. Disponível em: $<\mathrm{http}: / / \mathrm{www}$. sergiolessa.com>. . Mundo dos homens. São Paulo: Boitempo, 2002.

LUKÁCS, G. Ontologia dell'essere sociale. Roma: Riuniti, 1981. . Prolegômenos para uma ontologia do ser social. São Paulo: Boitempo, 2010.

. O marxismo ortodoxo. In: NETTO, J. P. (Org.). Lukács. São Paulo: Ática, 1992.

MARX, K. e ENGELS, F. A ideologia alemã. São Paulo: Hucitec, 1984.

. A ontologia de Marx: questões metodológicas preliminares. In: NETTO, J. P. (Org.).

Lukács. São Paulo: Ática, 1992.

A decadência ideológica e as condições gerais da pesquisa científica. In: NETTO, J. P. (Org.). Lukács. São Paulo: Ática, 1992. 
NETTO, J. Notas para a discussão e sistematização da prática e teoria em Serviço Social. Cadernos Abess, n. 3, 1989.

NETTO, J. P.; BRAZ, M. Economia política: uma introdução crítica. São Paulo: Cortez, 2006.

SEVERINO, A. J. O conhecimento pedagógico e a interdisciplinaridade: o saber como intencionalização da prática. In: FAZENDA, I. C. Arantes (Org.). Didática e interdisciplinaridade. Campinas: Papirus, 1998.

TONET, I. A questão dos fundamentos. In: . Educação, cidadania e emancipação humana. Ijuí: Unijuí, 2005. . Marxismo para o século XXI. In: Em defesa do futuro. Maceió: Edufal, 2005. 